\title{
22nd Annual Meeting of the Society for Computers in Psychology
}

St. Louis, Missouri

November 12, 1992

The 22nd Annual Meeting of the Society for Computers in Psychology will be held at The Adam's Mark Hotel in St. Louis on November 12, 1992, the day before the annual meeting of the Psychonomic Society. The meeting will include presentations, discussions, tutorials, and software and hardware demonstrations. The proceedings will be published in Behavior Research Methods, Instruments, \& Computers.

For further information regarding the conference, contact Peter Hornby or Margaret Anderson, Department of Psychology, SUNY/Plattsburgh, Plattsburgh, NY 12901 (phone, 518-561-3676; Bitnet, compsych @snyplava).

\section{3rd Annual Meeting of the Psychonomic Society \\ St. Louis, Missouri}

November 13, 14, and 15, 1992

The 33rd Annual Meeting of the Psychonomic Society will be held in St. Louis, November 13,14, and 15,1992 . The meetings will begin Friday morning and continue until Sunday at noon. The headquarters hotel will be The Adam's Mark Hotel, at Fourth and Chestnut Street.

The program and hotel reservation cards have been mailed to members and associates. A copy of the program will be published in the November issue of the Bulletin of the Psychonomic Society. Additional programs wil be available at the registration desk for $\$ 7.00$.

For further information, please contact the secretary-treasurer of the Society: Cynthia H. Null. P.O. Box 7104, San Jose, California 95150-7104 (telephone: 415-604-1260). 


\section{Change in Editorship \\ Memory \& Cognition}

Margaret Jean Intons-Peterson will complete her 4-year term as editor of Memory \& Cognition at the end of 1993. The Publications Committee of the Psychonomic Society are pleased to announce that Geoffrey Loftus has agreed to be the new editor as of January 1, 1994.

After January 1, 1993, manuscripts should be submitted to Geoffrey Loftus, Department of Psychology, University of Washington, Seattle, WA 98195.

\section{Change in Editorship \\ Perception \& Psychophysics}

C. W. Eriksen, who has been Editor of Perception \& Psychophysics since 1971, will be retiring at the end of 1993. The Publications Committee of the Psychonomic Society, however, take pleasure in announcing that Myron L. Braunstein has accepted the editorship as of January 1, 1994.

After January 1, 1993, manuscripts should be submitted to Myron L. Braunstein at the Department of Cognitive Sciences, School of Social Sciences, University of California, Irvine, CA 92717.

\section{Support for Cognitive Science Research National Institute of Mental Health}

The National Institute of Mental Health (NIMH) aims to support a wide range of basic research in the cognitive sciences as part of its effort to expand knowledge of fundamental aspects of human behavior and adaptation.

NIMH encourages proposals for basic research in such areas as perception, memory, knowledge, thinking, learning, language, and performance. Methods may include (but are not limited to) human and animal experimentation, computer simulation, and formal/computational analysis. Investigators may have backgrounds in psychology, computer science, linguistics, philosophy, or any other cognitive science.

Funding mechanisms include grants for research projects (of various sizes and durations), pre- and postdoctoral fellowships, institutional training grants, career scientist awards, and conference grants.

Questions about NIMH's support for cognitive science research can be directed to Rodney Cocking or Howard Kurtzman, Basic Behavioral and Cognitive Sciences Research Branch, National Institute of Mental Health, Room 11C-16, 5600 Fishers Lane, Rockville, MD 20857 (e-mail, kwh@cu.nih.gov; phone, (301)4439400; FAX, (301) 443-4822.) 